Elliot T. Forsyth, ${ }^{1}$ Miguel Maes, ${ }^{2}$ Joel M. Stoltzfus, ${ }^{3}$ and Frederic Bachelier ${ }^{4}$

\title{
Promoted Ignition and Burning Tests of Stainless Steel in Flowing and Nonflowing Oxygen
}

REFERENCE: Forsyth, E.T., Maes, M., Stoltzfus, J.M., and Bachelier, F., "Promoted Ignition and Burning Tests of Stainless Steel in Flowing and Nonflowing Oxygen," Flammability and Sensitivity of Materials in Oxygen-Enriched Atmospheres: Tenth Volume, ASTM STP 1454, T. A. Steinberg, H. D. Beeson, and B. E. Newton, Eds., ASTM International, West Conshohocken, PA, 2003.

\begin{abstract}
The Industry-Sponsored Metals Combustion Test Program 96-1 was coordinated through Wendell Hull \& Associates, Inc. on behalf of several contributing companies, and all design and testing was performed at the NASA White Sands Test Facility. Phase I of this test program studied the threshold pressure for self-sustained burning of various types and sizes of stainless steel rods in nonflowing oxygen, as observed in Standard Test Method for Determining the Combustion Behavior of Metallic Materials in Oxygen-Enriched Atmospheres (ASTM G 124-95). Phase II studied the ignition and propagation of burning of $316 \mathrm{~L}$ stainless steel rods and pipe in flowing gaseous oxygen. The test sample configurations were chosen to replicate previous promoted ignition and burning tests as well as to represent geometries and cross-sectional thicknesses common in industrial piping applications. The gas pressures and velocities for the test matrix were selected to generally compare with CGA G-4.4 guidelines for the use of stainless steel in oxygen service. This paper summarizes the results from the Phase I nonflowing oxygen tests and presents in detail the results of the Phase II flowing oxygen tests. The maximum sample burn-length is shown as a function of test pressure in Phase I and also as a function of gas velocity in Phase II. These results indicate that flowing oxygen, under the given test conditions, significantly affects maximum sample burn length as compared to nonflowing oxygen. Supplementary flowing oxygen test data on stainless steel rods from a follow-up test program are consistent with these results and are presented herein.
\end{abstract}

KEYWORDS: flowing oxygen, promoted ignition, burning, flammability, stainless steel, rods

\footnotetext{
${ }^{1}$ Technical Consultant, Oxygen Safety Consultants, Inc./Wendell Hull \& Associates, Inc., 1631 S. Delaware Ave., Tulsa, OK 74104.

${ }^{2}$ Project Engineer, NASA Laboratories Office, NASA Johnson Space Center, White Sands Test Facility, P. O. Box 20, Las Cruces, NM 88004.

${ }^{3}$ Project Engineer, NASA Laboratories Office, NASA Johnson Space Center, White Sands Test Facility, P. O. Box 20, Las Cruces, NM 88004.

${ }^{4}$ Leader of the Engineering Technical Commission, Air Liquide World Wide Engineering, 57 , Avenue Carnot, BP 313, 94503 Champigny-sur-Marne Cedex, France.
} 


\section{Introduction}

The Industry-Sponsored Metals Combustion Test Program 96-1 was coordinated through Wendell Hull \& Associates, Inc. on behalf of several contributing companies, and all design and testing was performed at the NASA Johnson Space Center (JSC) White Sands Test Facility (WSTF). Phase I of this test program studied the threshold pressure for propagation of burning of stainless steel rods in nonflowing oxygen.

Threshold pressure is the minimum gas pressure, at a specified oxygen concentration and ambient temperature, that supports self-sustained burning of a test sample after positive ignition, as observed in Standard Test Method for Determining the Combustion Behavior of Metallic Materials in Oxygen-Enriched Atmospheres (ASTM G 124). Because there are varying definitions for the minimum burn length required to qualify as "self-sustained burning," often the data are presented in terms of the maximum burn length, which is the maximum length that the test sample burns beyond the promoter region. Threshold pressure is then determined based on these data. This was the approach taken in both Phases I and II of this test program. Phase I results are summarized below as background information.

This paper presents results from Program 96-1 Phase II, which examined the ignition and propagation of burning $316 \mathrm{~L}$ stainless steel rods and pipe in flowing gaseous oxygen (GOX). The test sample configurations were chosen to replicate previous promoted ignition and burning tests as well as to represent geometries and cross-sectional thicknesses common in industrial piping applications. The gas pressures and velocities for the test matrix were selected to generally compare with CGA G-4.4 guidelines for the use of stainless steel in oxygen service [1]. Also presented in this paper are the results from a follow-up test program sponsored by Air Liquide. The follow-up study was conducted on 316L stainless steel rods and supplements the Program 96-1 data.

\section{Objectives}

The objectives of Phase II were to develop a test system to evaluate the effect of gas velocity and pressure on material flammability and to determine the maximum burn lengths of $316 \mathrm{~L}$ stainless steel rod and pipe test samples at various velocity/pressure combinations in flowing oxygen. A final objective was to compare the maximum burn lengths from flowing conditions to any previous nonflowing oxygen data.

\section{Background}

Materials selection is a very important element to reducing the risk of fire in oxygen systems. If flammable materials are used in an oxygen system where ignition sources are present, fires can occur. A flammable material, as used herein, is a material that will support self-sustained burning if ignited in a given configuration and environment. The primary data used to evaluate metals flammability in oxygen service come from a promoted ignition and burning test method, first developed by NASA WSTF [2], and now an ASTM standard test method, G 124. In accordance with this and similar methods, much data have been collected regarding metals flammability versus pressure (i.e., threshold pressure) in GOX. However, these data are generally based on a 
material's flammability in a nonflowing oxygen environment, as was Phase I of this test program.

Phase I test materials included $1 / 8$ in. $(0.32 \mathrm{~cm}$ ) diameter (dia) $316 \mathrm{H}$ and $316 \mathrm{~L}$, $1 / 4$ in. $(0.64 \mathrm{~cm})$ dia cast CF8M, and $1 / 2$ in. $(1.27 \mathrm{~cm})$ dia $316 \mathrm{~L}$. Table 1 summarizes the maximum burn lengths observed during Phase I testing in nonflowing oxygen. Several samples of each material were tested at each test pressure, but only the maximum burn length for any given material is listed as this is what defines the threshold pressure. This table shows that if a $1.0 \mathrm{in}$. $(2.54 \mathrm{~cm})$ minimum burn length qualifies as self-sustained burning, the threshold pressure for $1 / 8 \mathrm{in}$. $(0.32 \mathrm{~cm}) 316 \mathrm{H}$ is $<700 \mathrm{psi}(4.8 \mathrm{MPa})$, for $1 / 8$ in. $(0.32 \mathrm{~cm}) 316 \mathrm{~L}$ is 400 psi $(2.8 \mathrm{MPa})$, for $1 / 4$ in. $(0.64 \mathrm{~cm}) \mathrm{CF} 8 \mathrm{M}$ is 800 psi (5.5 MPa), and for $1 / 2$ in. $(1.27 \mathrm{~cm}) 316 \mathrm{~L}$ is $1200 \mathrm{psi}(8.3 \mathrm{MPa})$.

Table 1 - Summary of Program 96-1 Phase I test results.

\begin{tabular}{|c|c|c|c|c|c|}
\hline & WSTF \# & Description & $\begin{array}{l}\text { Test Pressure } \\
\text { psia }(\mathrm{MPa})\end{array}$ & $\begin{array}{c}\text { Pretest Sample } \\
\text { Length } \\
\text { in. }(\mathrm{cm})^{\mathrm{a}}\end{array}$ & $\begin{array}{l}\text { Max. Burn } \\
\text { Length } \\
\text { in. }(\mathrm{cm})^{b}\end{array}$ \\
\hline & $97-31619$ & $1 / 8$ in. $316 \mathrm{H}$ & $\begin{array}{c}2000(13.2) \\
1000(6.9) \\
700(4.8)\end{array}$ & $\begin{array}{l}6.2(15.75) \\
6.3(16.00) \\
6.3(16.00)\end{array}$ & $\begin{array}{c}6.2(15.75) \\
5.2(13.20) \\
1.7(4.32)\end{array}$ \\
\hline & $97-31575$ & $1 / 8$ in. $316 \mathrm{~L}$ & $\begin{array}{l}500(3.5) \\
400(2.8) \\
300(2.1)\end{array}$ & $\begin{array}{l}6.3(16.00) \\
6.3(16.00) \\
6.4(16.26)\end{array}$ & $\begin{array}{c}6.3(16.00) \\
1.3(3.30) \\
0.4(1.02)\end{array}$ \\
\hline & $97-31753$ & $1 / 4$ in. CF8M & $\begin{array}{l}1000(6.9) \\
800(5.5) \\
700(4.8)\end{array}$ & $\begin{array}{l}4.9(12.45) \\
4.9(12.45) \\
4.9(12.45)\end{array}$ & $\begin{array}{c}4.9(12.45) \\
1.5(3.81) \\
0.8(2.03)\end{array}$ \\
\hline & $97-31574$ & $1 / 2$ in. $316 \mathrm{~L}$ & $\begin{array}{c}1500(10.4) \\
1200(8.3) \\
1000(6.9)\end{array}$ & $\begin{array}{l}5.1(12.95) \\
4.8(12.19) \\
5.1(12.95)\end{array}$ & $\begin{array}{c}4.5(11.43) \\
2.1(5.33) \\
0.2(0.51)\end{array}$ \\
\hline \multicolumn{6}{|c|}{$\begin{array}{l}\text { Exposed pretest sample length, beyond the promoter region. } \\
\text { Maximum burn length is the longest burn length of all samples tested at the specified } \\
\text { conditions, calculated by subtracting posttest sample length from pretest sample } \\
\text { length. }\end{array}$} \\
\hline
\end{tabular}

Other promoted ignition and burning testing performed in nonflowing systems using $1 / 8$ in. $(0.32 \mathrm{~cm})$ dia 316 stainless steel (assumed $316 \mathrm{~L}$ ) rods showed partial to complete burning at a test pressure of approximately 500 psig (3.4 MPa) [3].

A history of promoted ignition and burning testing in flowing oxygen also exists; however, the data were generated under conditions of very low flow rates. The system used was designed to measure the threshold oxygen concentration needed for flame propagation (oxygen index) of metals [4]. Test samples were $1 / 8 \mathrm{in} .(0.32 \mathrm{~cm})$ dia $316 \mathrm{~L}$ 
rods in a system flowing $0.67 \mathrm{scfm}(20 \mathrm{slm})$ with a local velocity past the sample of less than $1 \mathrm{ft} / \mathrm{s}(0.3 \mathrm{~m} / \mathrm{s})$ and an oxygen concentration verified to be at or above 99.7 percent (nitrogen balance). The test system also preheated the test samples as part of the ignition process. These rods showed self-sustained burning at pressures down to $300 \mathrm{psig}$ (2.1 MPa), using an arbitrary burn criteria requiring less than $70 \%$ of the original sample length $(<6.89 \mathrm{~cm})$ to remain posttest. Another study performed using low-flow oxygen tested 316L rods in a high-purity oxygen ( 99.993 percent oxygen, argon balance) environment and observed self-sustained burning at $510 \mathrm{psig}$ (3.52 MPa) [5].

Most oxygen pressure systems are designed for flow. Metals flammability data in a flowing oxygen environment may differ from traditional metals flammability data generated in a nonforced flow environment. Through varying gas velocities and pressures, this study attempts to characterize how flow influences the burn length of $1 / 2$ in. $(1.27 \mathrm{~cm})$ dia $316 \mathrm{~L}$ stainless steel rods and thick-walled pipe.

\section{Experimental}

\section{Test System}

A new system was built specifically for these tests. Figure 1 shows the flowing oxygen promoted ignition and burning system schematic. The system is modeled after the nonflowing promoted ignition and burning apparatus described in ASTM G 124. The ASTM G-124 test system involves upward propagation in oxygen that is nonflowing except for flow from free convection. The flowing oxygen system used in Phase II testing involves counter-flowing oxygen with upward propagation of the burning flame front. It consists of a cylindrical chamber that can be pressurized to $4500 \mathrm{psi}$ (31 MPa). The chamber body is made from 304 stainless steel, and the interior is lined with copper to protect it from the burning metal samples. Near the inlet, there is a flow-straightening device made from $\mathrm{K} 500 \mathrm{Monel}^{\circledR, 5}$, and directly below it is a copper sample holder. The vent ports on either side of the chamber are lined with copper to protect them from sample slag. A copper quench filter prevents blowing slag from exiting through the vent ports, and a copper cup below the sample quenches the slag without damage to the chamber.

Variable-sized orifices can be placed in the vents to control the mass flow rate and chamber back pressure. To ignite the promoter, Pyrofuze ${ }^{\circledR 6}$ wire is attached to two copper terminals that extend down from the top of the chamber, each attached to a Kemlon ${ }^{\circledR 7}$ electrical feed-through. A sapphire crystal view-window is mounted in the chamber wall with copper crush washers that provide a sealing surface. The window is housed in a Monel boss flange view port. A borescope lens connected to a video camera is mounted to this view port to record the tests.

${ }^{5} \mathrm{Monel}^{\circledR}$ is a registered trademark of Inco Alloys International, Inc., New Hartford, NY.

${ }^{6}$ Pyrofuze ${ }^{\circledR}$ is a registered trademark of Pyrofuze Corp., Mt. Vernon, NY.

${ }^{7} \mathrm{Kemlon}^{\circledR}$ is a registered trademark of Kemlon Products and Development Corp., Pearland, TX. 


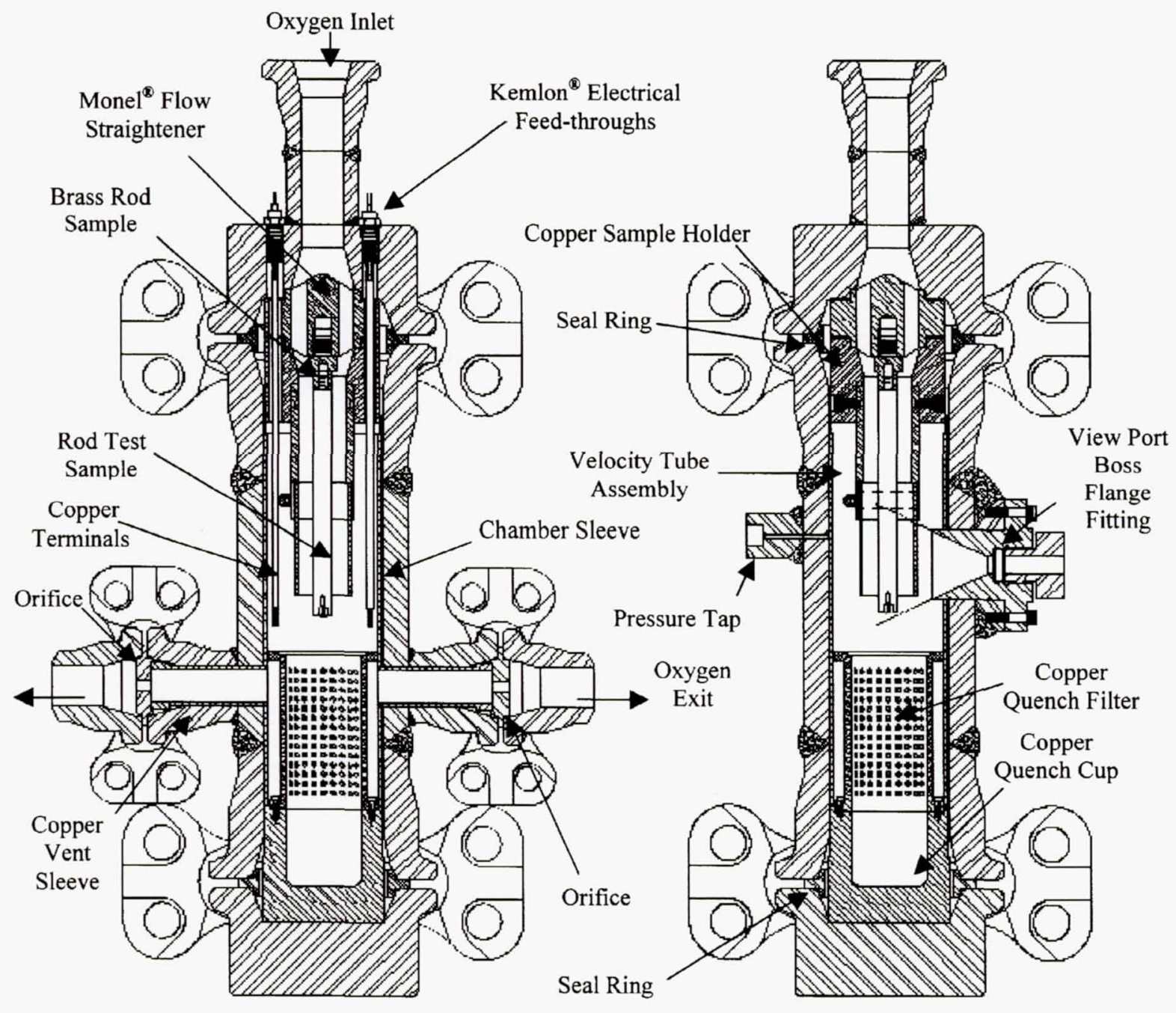

Figure 1 - WSTF Flowing Oxygen Promoted Ignition and Burning System [front view (left) and side view (right), total height $\sim 24 \mathrm{in} / 61 \mathrm{~cm}$ ].

The system can accommodate both rod and pipe test samples. Test samples are held vertically and are supported at the top from the copper sample holder with setscrews. The velocity tube assembly, consisting of a copper upper section and a quartz lower section, is placed around a rod sample and clamped into the sample holder. The test gas flows through the annulus created by the outside diameter of the sample and the inside diameter of the velocity tube. The quartz section allows visual inspection of the sample during the test while providing the required inside diameter for setting gas velocity. Quartz also has an extremely low coefficient of thermal expansion, which keeps it from cracking or breaking if it comes into contact with molten metal. For tests using pipe samples, the rod sample and velocity tube assembly shown in Figure 1 are replaced by the pipe sample, and oxygen flows through the inside diameter of the pipe sample.

The system is located in the WSTF High-Pressure Test Area, which supplies GOX at pressures up to $6000 \mathrm{psi}(41 \mathrm{MPa})$, temperatures up to $1000^{\circ} \mathrm{F}\left(540^{\circ} \mathrm{C}\right)$, and mass flow rates up to $8 \mathrm{lbm} / \mathrm{s}(3.6 \mathrm{~kg} / \mathrm{s})$. The oxygen concentration for this test system is verified to 
be at least 99.5 percent, which meets the minimum specified in MIL-PRF-27210G for Aviator's Breathing Oxygen (ABO) [6]. A pressure transducer was tapped into the chamber wall, opposite the view window, to record the test pressure.

\section{Sample Configuration and Material}

All rod and pipe samples were approximately 6 in. $(15.2 \mathrm{~cm})$ in length and were certified to be $316 \mathrm{~L}$ stainless steel. The samples were cleaned and prepared for test per NASA-STD-6001 [7].

Figure 2 shows a sketch of a typical $1 / 2$ in. $(1.27 \mathrm{~cm})$ dia Phase II rod test sample and two photos of the promoter assembly. A threaded section on the top of the test sample fastened it to the sample holder. The test sample bottom was machined to encapsulate a standard magnesium or aluminum promoter, as specified in ASTM G 124, protecting it from flow during ignition. The promoter was held in place by an aluminum machine screw, which increased the ignition energy when ignited by the Pyrofuze wire.
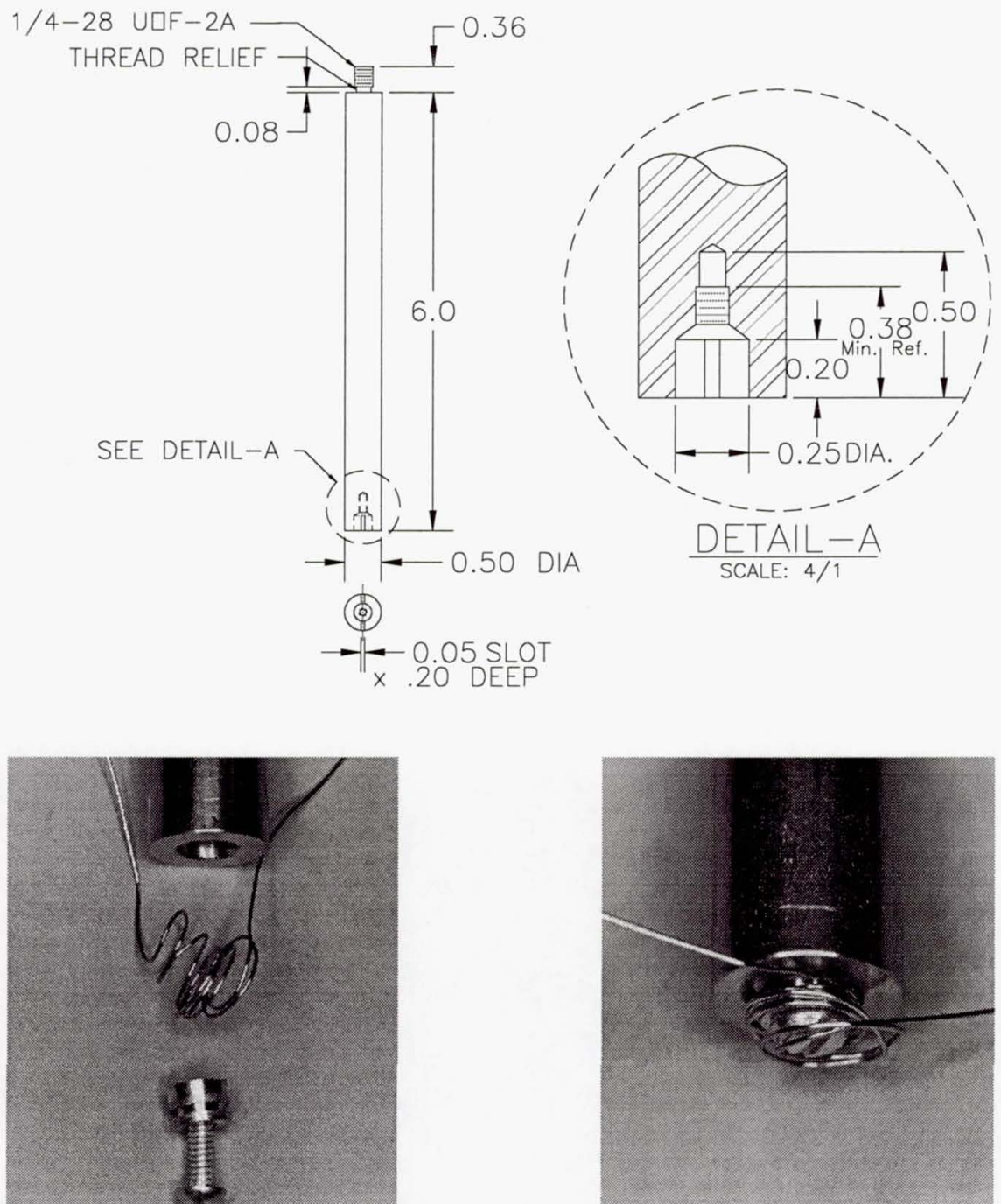

Figure 2 - Rod samples and promoter for Phase II (all dimensions in inches). 
Figure 3 shows the two pipe sample configurations. Two schedules of pipe were tested: $11 / 4$ in. Sch. $80(0.191$ in. $(0.485 \mathrm{~cm})$ wall $)$ and $11 / 4$ in. Sch. XXS (0.382 in. $(0.970 \mathrm{~cm})$ wall $)$. A notch was cut into the top of each sample to accommodate the sample holder setscrew. The bottom of each pipe sample was machined for two different promoter configurations: \#1, in which an aluminum ring promoter was press-fit on the outside diameter, and \#2, which was used on some of the Sch. XXS samples and had an annulus machined in the bottom end of the sample to allow the same aluminum ring igniter to be slip-fit inside the end of the sample and held in place by four small aluminum machine screws.

\section{Results and Discussion}

Much of Phase II testing included new sample sizes and configurations never before tested. Thus, a rigorous part of the testing consisted of developing new ignition promoters that would consistently ignite test samples in given environments. This development was a mandatory prerequisite to studying the propagation of the burning samples.

One difficulty encountered in testing these larger diameter rod and pipe samples was that in many tests, the promoter kindled only a portion of the sample around the igniter cavity, leaving a question as to whether the sample had been positively ignited. For the purpose of reporting the results of this study, the commonly accepted criteria for positive ignition was applied, which requires that the promoter ignite and burn away and, at minimum, completely burn the test sample surrounding or surrounded by the promoter.
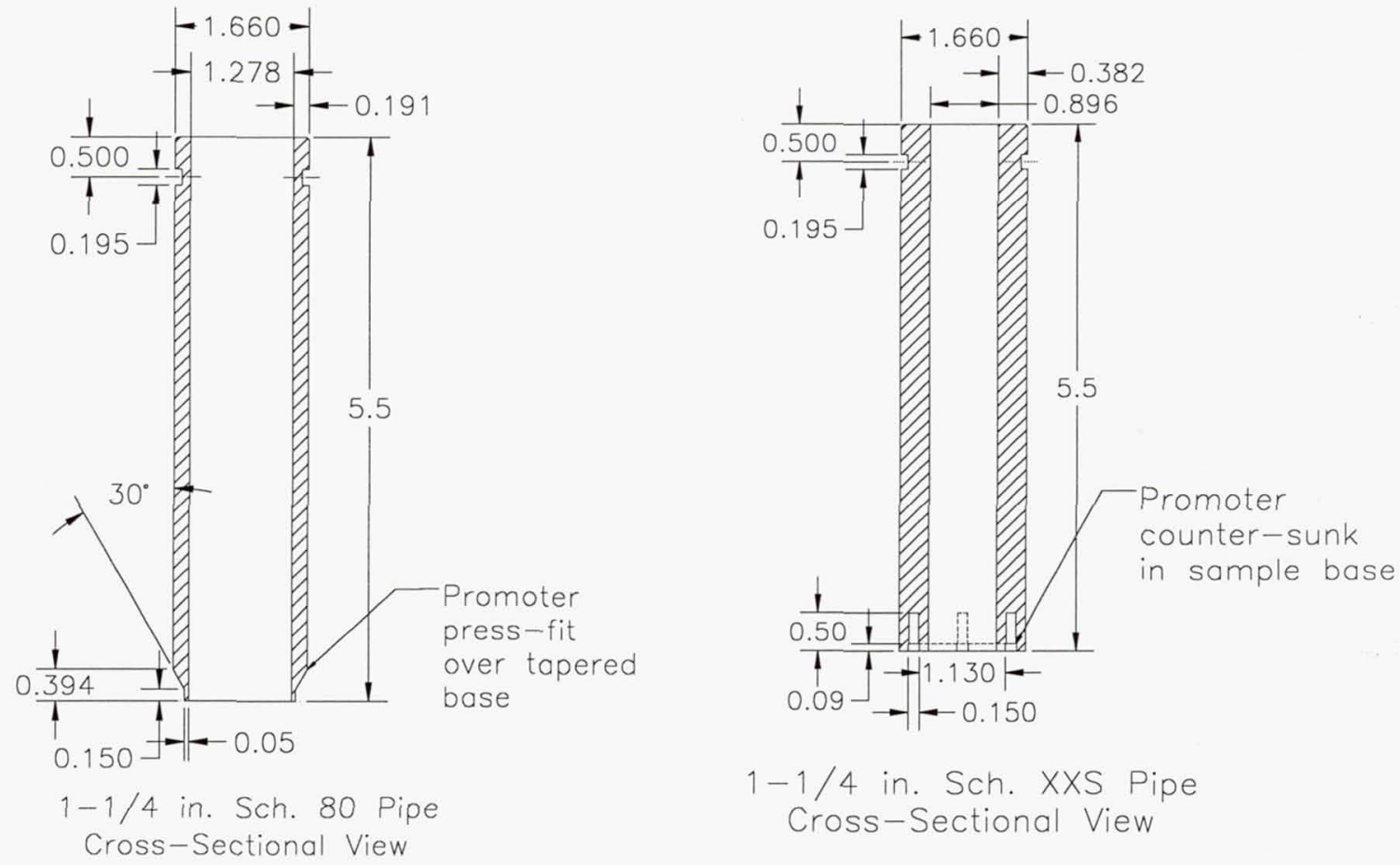

Figure 3 - Phase II pipe samples, configuration \#1 (left) and \#2 (right) (all dimensions in inches). 
Thus, positive ignition requirement lengths are configuration-specific and vary between the rods and pipe samples. For the rods, positive ignition required that the sample be completely burned at least past the promoter cavity and screw hole, or a length of approximately $0.5 \mathrm{in} .(1.3 \mathrm{~cm})$ (Figure 2$)$. For the pipe samples with the Al promoter press-fit on the tapered outside diameter, positive ignition required that the sample be consumed at least past the promoter length and tapered section, or approximately $0.4 \mathrm{in}$. $(1.0 \mathrm{~cm})$ (Figure 3$)$. For the Sch. XXS pipe samples with the Al promoter countersunk into the sample bottom, positive ignition required that the sample be consumed past the promoter cavity and screw holes, or approximately 0.5 in. $(1.3 \mathrm{~cm})$ (Figure 3$)$. The promoter ignition energies were calculated and compared to the theoretical energy required to melt/ignite the end of the sample for each configuration tested in an attempt to maximize the number of positive ignitions for the conditions tested.

Burn length, sometimes called propagation length, is the length of the test sample consumed beyond the promoter region. Large-diameter samples can undergo unsymmetrical burning around the sample diameter, consuming one side of the sample more than the other. The sample burn length reported for these samples was measured to the midpoint between the points of least and greatest burning around the end of the sample.

\section{1/2 in. dia Rod Test Sample Data}

Table 2 summarizes the Phase II flowing oxygen test data for the rod samples. Phase I nonflowing oxygen testing showed the $1 / 2 \mathrm{in} .(1.27 \mathrm{~cm})$ dia $316 \mathrm{~L}$ rods had a maximum burn length of only $0.2 \mathrm{in.}(0.51 \mathrm{~cm})$ at $1000 \mathrm{psia}(6.9 \mathrm{MPa})$ (Table 1$)$. Phase II tests with $50 \mathrm{ft} / \mathrm{s}(15 \mathrm{~m} / \mathrm{s})$ flowing oxygen at $500 \mathrm{psia}(3.4 \mathrm{MPa})$ showed complete burning (Table 2). Thus, the effect of flow on sample ignition and burning is significant at these pressures and gas velocities. Figure 4 shows a posttest photograph of the 500 psi (3.4 MPa), $50 \mathrm{ft} / \mathrm{s}(15 \mathrm{~m} / \mathrm{s})$ rod samples. These conditions showed the most extensive burning of any of the rod test conditions. As indicated in Table 2, the maximum burn length from this test condition was a complete sample burn, or $4.81 \mathrm{in} .(12.2 \mathrm{~cm})$.

Table 2 - Summary of results for Phase 11 1/2-in. $(1.27 \mathrm{~cm})$ rod test samples.

\begin{tabular}{ccccc}
\hline Pressure & Velocity & $\begin{array}{c}\text { \# of Tests } \\
\text { Performed }\end{array}$ & $\begin{array}{c}\text { \# of Positive } \\
\text { Ignitions }\end{array}$ & $\begin{array}{c}\text { Maximum Burn } \\
\text { Length } \\
\text { in. }(\mathrm{cm})\end{array}$ \\
\hline $500(3.4)$ & $50(15)$ & 11 & 7 & $4.81(12.22)^{\mathrm{a}}$ \\
$500(3.4)$ & $100(30)$ & 9 & 2 & $0.40(1.02)$ \\
$500(3.4)$ & $200(60)$ & 5 & 0 & No burn \\
$1000(6.9)$ & $50(15)$ & 9 & 2 & $0.36(0.91)$ \\
$1000(6.9)$ & $100(30)$ & 5 & 0 & No burn \\
$1500(10.3)$ & $50(15)$ & 7 & 0 & No burn \\
\hline
\end{tabular}

${ }^{\text {a }}$ Complete burning of the test sample. 


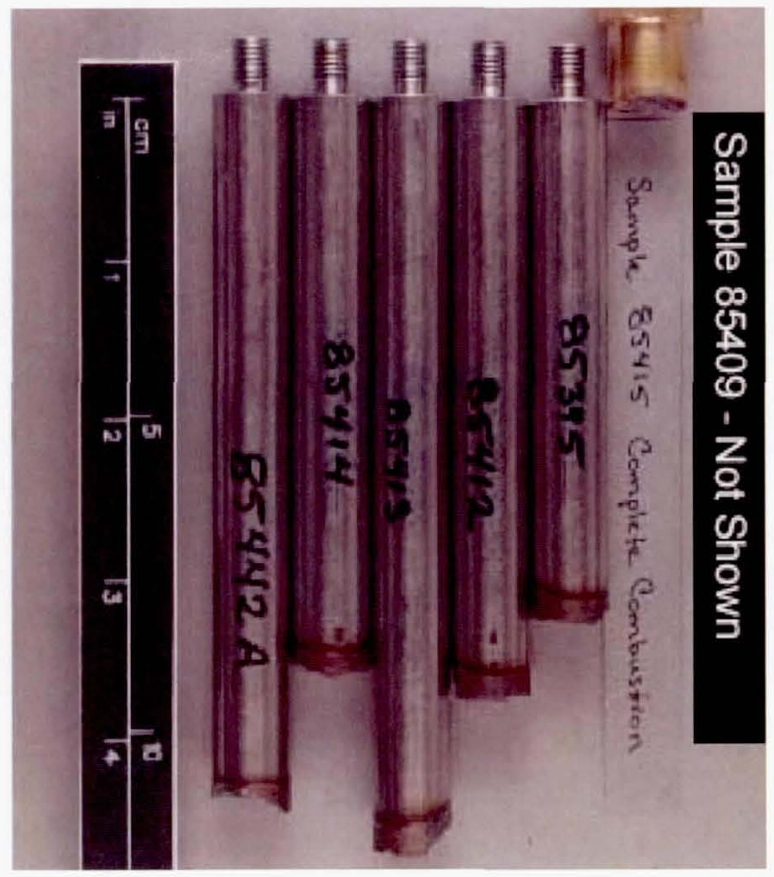

Figure 4 - Posttest photograph of $1 / 2 \mathrm{in} .(1.27 \mathrm{~cm})$ dia stainless steel $316 \mathrm{~L} \mathrm{rod} \mathrm{test}$ samples from $500 \mathrm{psi}(3.4 \mathrm{MPa}), 50 \mathrm{ft} / \mathrm{s}(15 \mathrm{~m} / \mathrm{s})$ conditions.

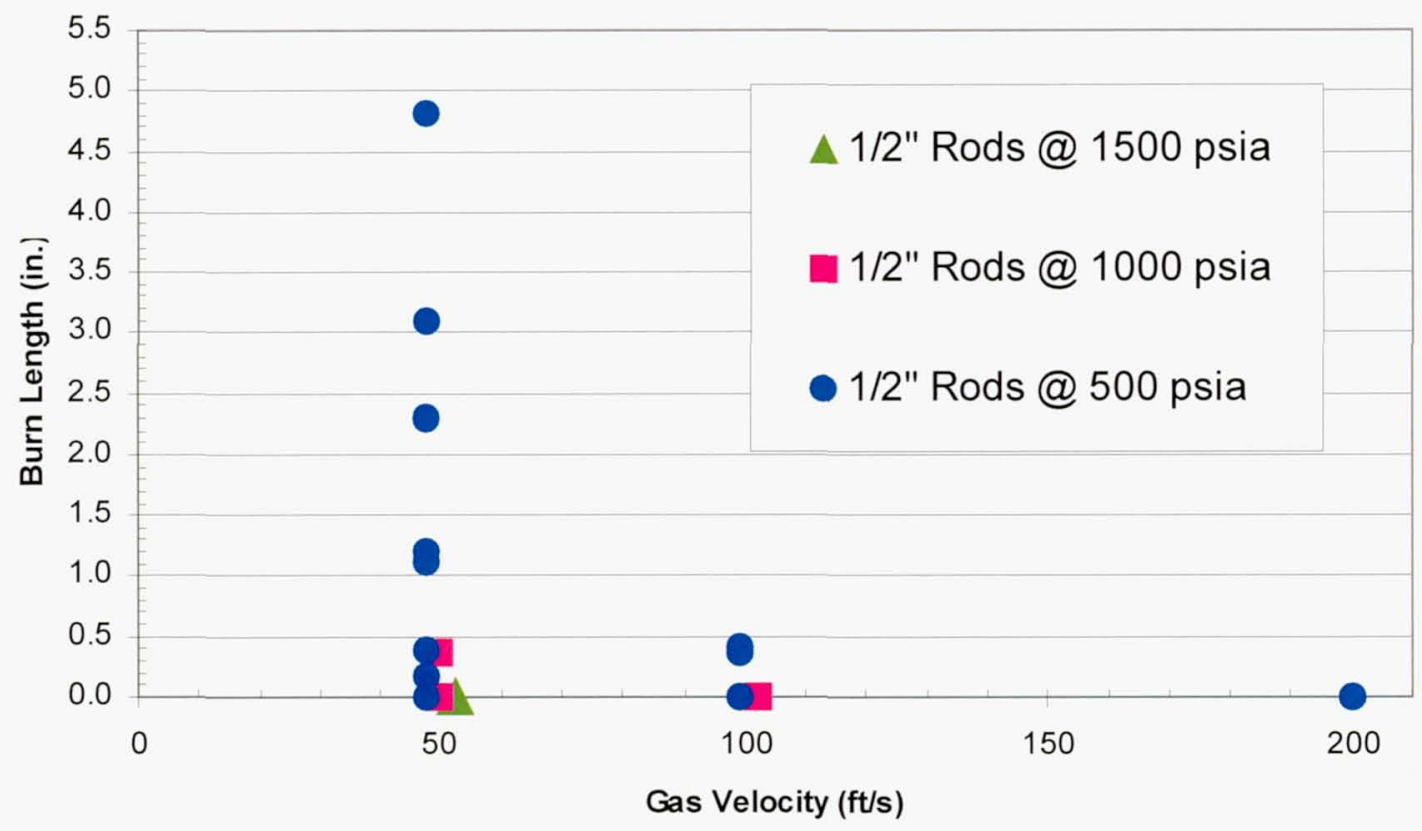

Figure 5 - Phase II results of $1 / 2$ in. dia stainless steel $316 L$ rod test samples. 
Figure 5 shows the burn lengths of each test graphed against gas velocity for testing at 500,1000 , and 1500 psia, respectively $(3.4,6.9$, and $10.3 \mathrm{MPa})$. Burn length was measured from beyond the promoter region, and tests failing to meet the positive ignition criteria are shown as a zero burn length. The data indicate that burn length decreases with increasing gas velocity above $50 \mathrm{ft} / \mathrm{s}(15 \mathrm{~m} / \mathrm{s})$ at 500 and $1000 \mathrm{psia}(3.4$ and 6.9 $\mathrm{MPa})$. The data also show a decrease in burn length as pressure increases from 500 to $1000 \mathrm{psia}(3.4$ to $6.9 \mathrm{MPa}$ ) at both 50 and $100 \mathrm{ft} / \mathrm{s}(15$ and $30 \mathrm{~m} / \mathrm{s})$. However, it is important to note that the samples were also more difficult to ignite as gas velocity increased above $50 \mathrm{ft} / \mathrm{s}(15 \mathrm{~m} / \mathrm{s})$, with only a few positive ignitions seen at test conditions above $500 \mathrm{psi}(3.4 \mathrm{MPa})$ and $50 \mathrm{ft} / \mathrm{s}(15 \mathrm{~m} / \mathrm{s})$ (Table 2$)$.

Though these tests did not produce a large quantity of burn propagation data, the data do show that gas flow has a significant effect on sample ignition. Specifically, the data indicate that as flow conditions increased above $500 \mathrm{psi}(3.4 \mathrm{MPa})$ and $50 \mathrm{ft} / \mathrm{s}(15 \mathrm{~m} / \mathrm{s})$, the number of positive ignitions using this configuration decreased.

The observed decrease in positive ignitions and burn length with increasing pressure contrasts what is observed in nonflowing test environments in which burn length increases with increasing pressure. One mechanism for heat transfer in this test configuration is to the environment through the surrounding gas. As pressure increases, the gas density increases and heat produced in and around the small-diameter sample can be more readily transferred away from the sample because thermal conductivity and heat transfer coefficient increases with density. In nonflowing test environments, however, data show that at higher pressures, the increased reaction rate generates greater heat flux into the sample than heat loss into the surrounding environment, despite the increased gas density. Thus, burn lengths increased with increasing pressure. In flowing gas environments, heat can be transferred away from the sample through different mechanisms. As gas velocity increases, the effect of convective forces becomes more pronounced, acting to cool the sample, though this is highly configuration-dependent. Further, the configuration of the rod sample in the tester may have created certain flow dynamics relative to the sample that were especially favorable to ignition and burning at $50 \mathrm{ft} / \mathrm{s}(15 \mathrm{~m} / \mathrm{s})$ and not at higher gas velocities.

\section{1/4 in. Sch. 80 SS Pipe Test Sample Data}

The $11 / 4$ in. Sch. 80 pipe samples were added to the program to evaluate the effect of pipe wall thickness on ignition and burn propagation. Table 3 summarizes the results from the Sch. 80 pipe samples. Figure 6 shows four of the five posttest samples from testing at $1000 \mathrm{psia}(6.9 \mathrm{MPa}), 100 \mathrm{ft} / \mathrm{s}(30 \mathrm{~m} / \mathrm{s})$. Minimal burn lengths were observed, as the original sample length was approximately $5.5 \mathrm{in} .(13.97 \mathrm{~cm})$. In many of these samples, the promoter burned a portion of the tapered section of the sample but failed to propagate upward, burning past the major wall thickness. 
Table 3 - Summary of results for Phase II Sch. 80 pipe test samples.

\begin{tabular}{|c|c|c|c|c|}
\hline $\begin{array}{c}\text { Pressure } \\
\text { psia (MPa) }\end{array}$ & $\begin{array}{l}\text { Velocity } \\
\mathrm{ft} / \mathrm{s}(\mathrm{m} / \mathrm{s})\end{array}$ & $\begin{array}{l}\text { \# of Tests } \\
\text { Performed }\end{array}$ & $\begin{array}{l}\text { \# of Positive } \\
\text { Ignitions }\end{array}$ & $\begin{array}{l}\text { Maximum Burn } \\
\text { Length } \\
\text { in. }(\mathrm{cm}) \\
\end{array}$ \\
\hline $500(3.4)$ & $50(15)$ & 4 & 4 & $0.19(0.48)$ \\
\hline $500(3.4)$ & $100(30)$ & 5 & 5 & $0.40(1.02)$ \\
\hline $500(3.4)$ & $200(60)$ & & No tests performed & \\
\hline $1000(6.9)$ & $50(15)$ & & No tests performed & \\
\hline $1000(6.9)$ & $100(30)$ & 5 & 1 & $0.04(1.02)$ \\
\hline $1500(10.3)$ & $50(15)$ & & No tests performed & \\
\hline
\end{tabular}

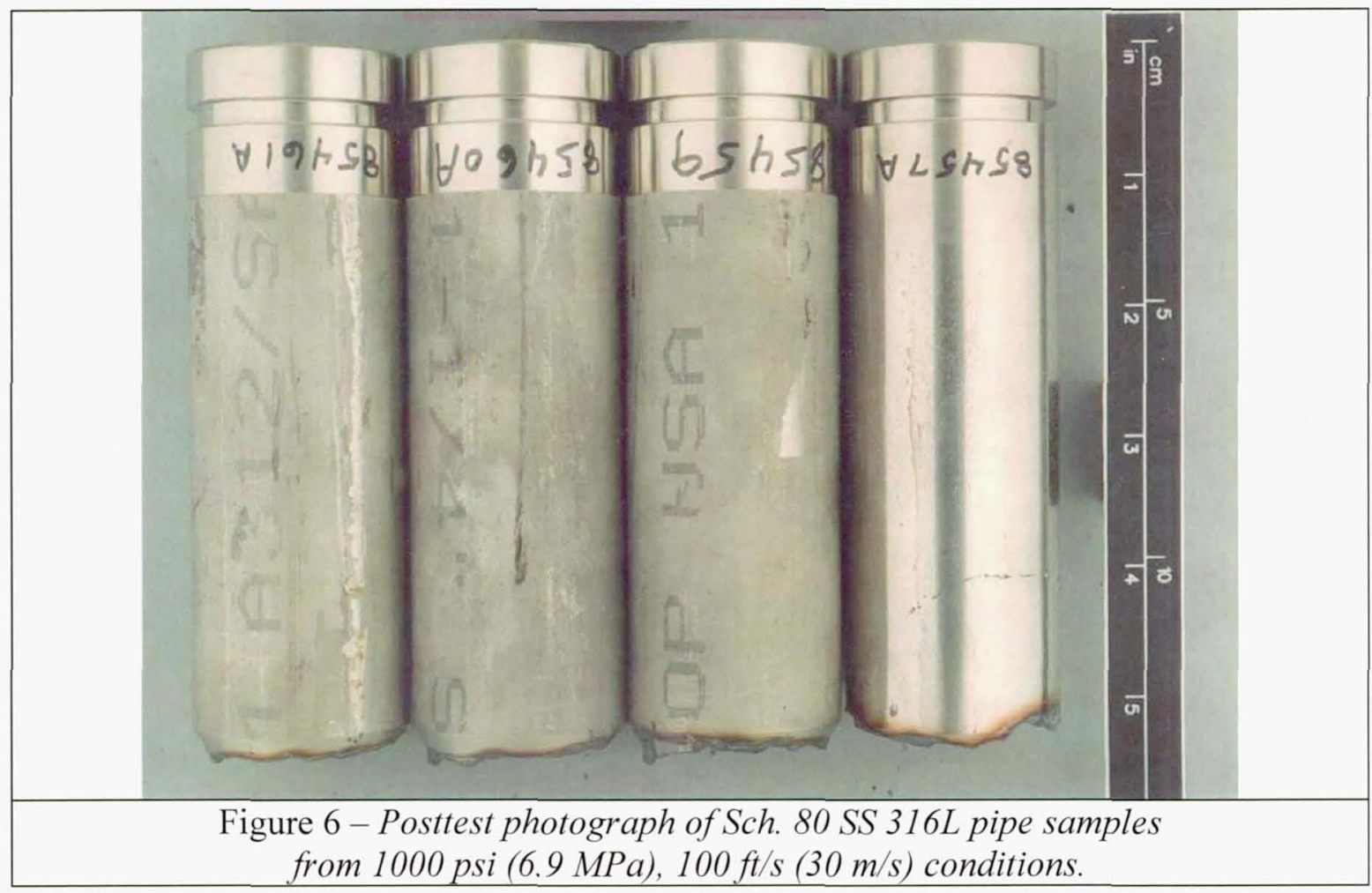

Figure 7 shows the burn lengths of each positive ignition test graphed against gas velocity for testing at 500 and $1000 \mathrm{psi}(3.4$ and $6.9 \mathrm{MPa})$. The data show minimal burn lengths at each condition. Though the potential heat input by the promoter configuration in these tests was nearly three times that required to melt and ignite the tapered section of pipe, most tests did not meet positive ignition criterion. Thus, the Sch. 80 pipe samples proved difficult to ignite with this promoter configuration at these test conditions, even with a large ignition source. The effect of varying pressure from 500 to $1000 \mathrm{psi}$ (3.4 to $6.9 \mathrm{MPa}$ ) or varying the gas velocity from 50 to $100 \mathrm{ft} / \mathrm{s}(15$ to $30 \mathrm{~m} / \mathrm{s})$ did not significantly increase burn propagation of the samples. In fact, the burn lengths at $1000 \mathrm{psi}(6.9 \mathrm{MPa})$ and $100 \mathrm{ft} / \mathrm{s}(30 \mathrm{~m} / \mathrm{s})$ were generally smaller than those at $500 \mathrm{psi}$ $(3.4 \mathrm{MPa})$ and $100 \mathrm{ft} / \mathrm{s}(30 \mathrm{~m} / \mathrm{s})$. 


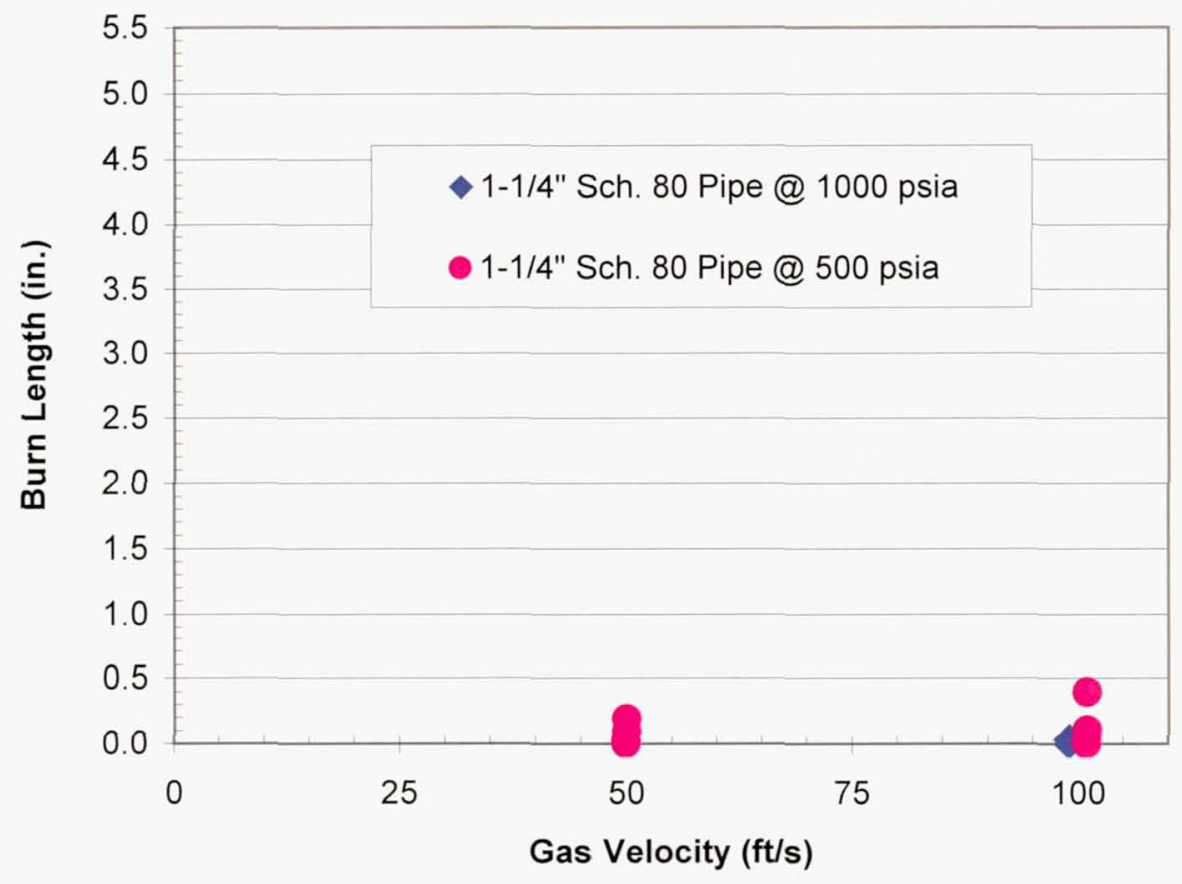

Figure 7 - $11 / 4$ in. Sch. 80 SS 316 L pipe results.

In comparing the burn lengths of $1 / 2$ in. $(1.27 \mathrm{~cm})$ dia rod samples to $\mathrm{Sch} .80$ pipe samples, the burn lengths of rod samples were greatest where the pressure (thus, gas density) and velocity were lower. In contrast, the Sch. 80 pipe samples had small burn lengths under these conditions. At higher pressures/velocity combinations, the burn lengths for the rods were small, as they were for the Sch. 80 pipe samples. The promoter and sample configuration appear to have a significant influence on burn length. Though rod samples had a comparatively thicker cross-section to ignite $(1 / 2 \mathrm{in}$. $(1.27 \mathrm{~cm})$ dia rod vs. 0.191 in. $(0.49 \mathrm{~cm})$ wall pipe), they required a smaller promoter energy and produced significantly larger burn lengths at test conditions. The rod promoter was encapsulated inside the sample bottom and protected from flow over the rod's outside diameter. This configuration was more effective in transferring heat from the burning promoter into the test sample than Sch. 80 pipe with the promoter pressed onto the outside diameter of the sample, which allowed more of the promoter ignition energy to be lost to the surrounding environment. The difference in promoter configuration affected ignition of the Sch. 80 pipe test samples, showing the resistance of $316 \mathrm{~L}$ stainless steel pipe to ignition in these test conditions. Furthermore, if gas flow had been over the outside diameter of the Sch. 80 pipe samples instead of through the internal diameter, the configuration would have been more similar to the rod samples, and the results may have been more similar to those of the rod samples.

\section{1/4 in. Sch. XXS Pipe Test Sample Data}

Table 4 shows the results of the Sch. XXS pipe data. All of these tests failed to promote ignition in the test sample past the promoter region. Using the $0.5 \mathrm{in} .(1.27 \mathrm{~cm})$ positive ignition criterion, the closest any sample came to positive ignition was a 0.49 in. 
Table 4 - Summary of results for Phase II Sch. XXS pipe test samples.

\begin{tabular}{|c|c|c|c|c|}
\hline $\begin{array}{c}\text { Pressure } \\
\text { psia }(\mathrm{MPa})\end{array}$ & $\begin{array}{l}\text { Velocity } \\
\mathrm{ft} / \mathrm{s}(\mathrm{m} / \mathrm{s})\end{array}$ & $\begin{array}{l}\text { \# of Tests } \\
\text { Performed }\end{array}$ & $\begin{array}{l}\text { \# of Positive } \\
\text { Ignitions }\end{array}$ & $\begin{array}{l}\text { Maximum Burn } \\
\text { Length } \\
\text { in. }(\mathrm{cm})\end{array}$ \\
\hline $500(3.4)$ & $50(15)$ & 5 & 0 & 0 \\
\hline $500(3.4)$ & $100(30)$ & 6 & 0 & 0 \\
\hline $500(3.4)$ & $200(60)$ & 6 & 0 & 0 \\
\hline $1000(6.9)$ & $50(15)$ & 9 & 0 & 0 \\
\hline $1000(6.9)$ & $100(30)$ & 5 & 0 & 0 \\
\hline $1500(10.3)$ & $50(15)$ & 5 & 0 & 0 \\
\hline
\end{tabular}

$(1.24 \mathrm{~cm})$ burn at $500 \mathrm{psi}(3.4 \mathrm{MPa})$ and $200 \mathrm{ft} / \mathrm{s}(60 \mathrm{~m} / \mathrm{s})$. During one test at this same test condition, a fire occurred in the system that destroyed the original test chamber. It was determined that a drop of burning metal was blown onto an unprotected section of the stainless steel chamber wall, kindling and burning through the chamber. Thus, this test cannot be counted in the data set as it is unknown whether the sample had propagated before kindling to the chamber wall. A second chamber was built to complete the test program.

Figure 8 shows posttest samples from the $500 \mathrm{psia}(3.4 \mathrm{MPa}), 50 \mathrm{ft} / \mathrm{s}(15 \mathrm{~m} / \mathrm{s})$ testing. No positive ignitions were observed in these samples. Like the Sch. 80 samples, the Sch. XXS samples were difficult to ignite and showed very limited burning. The promoter energy and configuration were critical factors affecting sample ignition and, ultimately, sample burn length. The promoter configuration was changed from the Sch. 80 pipe tests to recess the aluminum ring into the end of the sample. In addition, the promoter assembly's total energy was increased with the addition of aluminum set screws. These changes were designed to allow a greater promoter ignition energy to be more effectively transferred to the test sample and less heat lost to the surrounding environment. Even with these changes, the increased sample wall thickness $(0.382$ in. $(0.97 \mathrm{~cm})$ wall for $\mathrm{Sch}$. XXS pipe vs. $0.191 \mathrm{in} .(0.49 \mathrm{~cm})$ wall for Sch. 80 pipe $)$ made these samples difficult to ignite in this configuration.

\section{Supplementary Flowing Oxygen Testing on Stainless Steel Rods}

The results of Program 96-1 Phase II generated significant interest within industry to pursue additional flowing oxygen promoted ignition testing, especially concerning stainless steel rods. Air Liquide Corporation provided the funding to continue testing $1 / 2$-in. $(1.27 \mathrm{~cm})$ dia $316 \mathrm{~L}$ stainless steel rods at lower pressures and velocities to those that showed self-sustained burning in the Phase II tests. Table 5 shows the results of these supplementary data. Limited numbers of tests were performed at each condition in an effort to study more pressure and velocity combinations. 


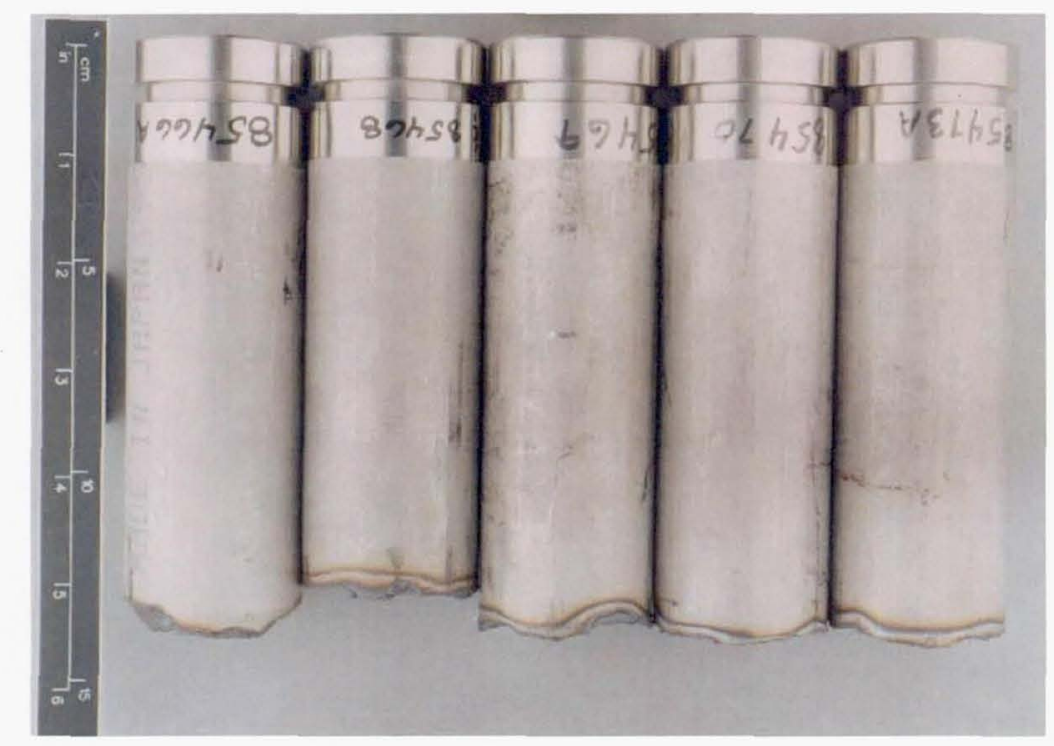

Figure 8 - Posttest Sch. XXS pipe test samples from 500 psi (3.4 MPa), $50 \mathrm{ft} / \mathrm{s}(15 \mathrm{~m} / \mathrm{s})$ conditions.

Table 5 - Summary of results for supplementary 1/2-in. $(1.27 \mathrm{~cm})$ rod test samples.

\begin{tabular}{ccccc}
\hline Pressure & Velocity & $\begin{array}{c}\text { \# of Tests } \\
\text { Performed }\end{array}$ & $\begin{array}{c}\text { \# of Positive } \\
\text { Ignitions }\end{array}$ & $\begin{array}{c}\text { Maximum Burn } \\
\text { Length } \\
\text { in. }(\mathrm{cm})\end{array}$ \\
\hline psia (MPa) & $\mathrm{ft} / \mathrm{s}(\mathrm{m} / \mathrm{s})$ & 3 & 3 & $2.50(6.35)$ \\
$500(3.4)$ & $50(15)$ & 4 & 2 & $1.20(3.05)$ \\
$450(3.1)$ & $55(17)$ & 3 & 2 & $3.13(7.95)$ \\
$450(3.1)$ & $29(8.8)$ & 3 & 3 & $1.34(3.40)$ \\
$400(2.8)$ & $29(8.8)$ & 3 & 1 & $1.27(3.23)$ \\
$350(2.4)$ & $29(8.8)$ & 3 & 1 & $0.57(1.45)$ \\
$300(2.1)$ & $29(8.8)$ & & & \\
\hline
\end{tabular}

Figure 9 shows the burn lengths of each test graphed against gas velocity for these pressures. Ignition and sustained burning of the $1 / 2-$ in $(1.27 \mathrm{~cm})$ dia $316 \mathrm{~L}$ stainless steel rods were observed at even lower pressure/velocity combinations than previously tested in Phase II. When the gas velocity was reduced by almost half, from 55 to $29 \mathrm{ft} / \mathrm{s}$ ( 17 to $8.8 \mathrm{~m} / \mathrm{s})$, at $450 \mathrm{psi}(3.1 \mathrm{MPa})$, the burn length increased dramatically. Assuming a 1.0 in. $(2.54 \mathrm{~cm})$ minimum burn length qualifies as self-sustained burning, at the $29 \mathrm{ft} / \mathrm{s}(8.8$ $\mathrm{m} / \mathrm{s}$ ) velocity condition self-sustained burning was observed in samples down to $350 \mathrm{psi}$ (2.4 MPa), significantly less than the $1200 \mathrm{psi}(8.27 \mathrm{MPa})$ threshold pressure shown for a nonflowing oxygen environment in Table 1. The data suggests that for a given sample, flowing oxygen under these conditions can potentially reduce the threshold pressure for burning by nearly 70 percent compared to the threshold pressure in nonflowing oxygen. 


\section{Conclusions and Recommendations}

The objective of the Industry-Sponsored Metals Combustion Test Program 96-1 Phase II testing was fulfilled through the design and development of a flowing oxygen test system. The testing proved successful as three different test sample configurations were subjected to varying gas pressures and velocities to compare burn propagation lengths in these environments.

One specific objective was to compare the maximum burn lengths of $316 \mathrm{~L}$ stainless steel rods at various pressures in flowing oxygen to the maximum burn lengths of $316 \mathrm{~L}$ stainless steel rods from Phase I testing at similar pressures in nonflowing oxygen. The Phase II and supplementary tests on $1 / 2$ in. $(1.27 \mathrm{~cm})$ dia rods showed significant burning at the lower pressure-velocity environments, including one complete sample burn at $500 \mathrm{psia}(3.4 \mathrm{MPa})$ and $50 \mathrm{ft} / \mathrm{s}(15 \mathrm{~m} / \mathrm{s})$, and other self-sustained burns (burn lengths $>1.0 \mathrm{in}$. $(2.54 \mathrm{~cm}))$ down to $350 \mathrm{psi}(2.4 \mathrm{MPa})$ and $29 \mathrm{ft} / \mathrm{s}(8.8 \mathrm{~m} / \mathrm{s})$. These data are significant in that they show a near 70 percent reduction in the flammability threshold pressure of these samples in flowing oxygen as compared to the Phase I nonflowing test results.

The $1 / 2$ in. $(1.27 \mathrm{~cm})$ rod data also indicate that burn length decreased with increasing gas velocity above $50 \mathrm{ft} / \mathrm{s}(15 \mathrm{~m} / \mathrm{s})$ at 500 and $1000 \mathrm{psia}(3.4$ and $6.9 \mathrm{MPa})$. Further, the data show a decrease in burn length as pressure increased from 500 to 1000 psia (3.4 to $6.9 \mathrm{MPa}$ ) at both 50 and $100 \mathrm{ft} / \mathrm{s}(15$ and $30 \mathrm{~m} / \mathrm{s})$. It was also observed that the samples were more difficult to ignite as gas velocity increased above $50 \mathrm{ft} / \mathrm{s}(15 \mathrm{~m} / \mathrm{s})$, with only a

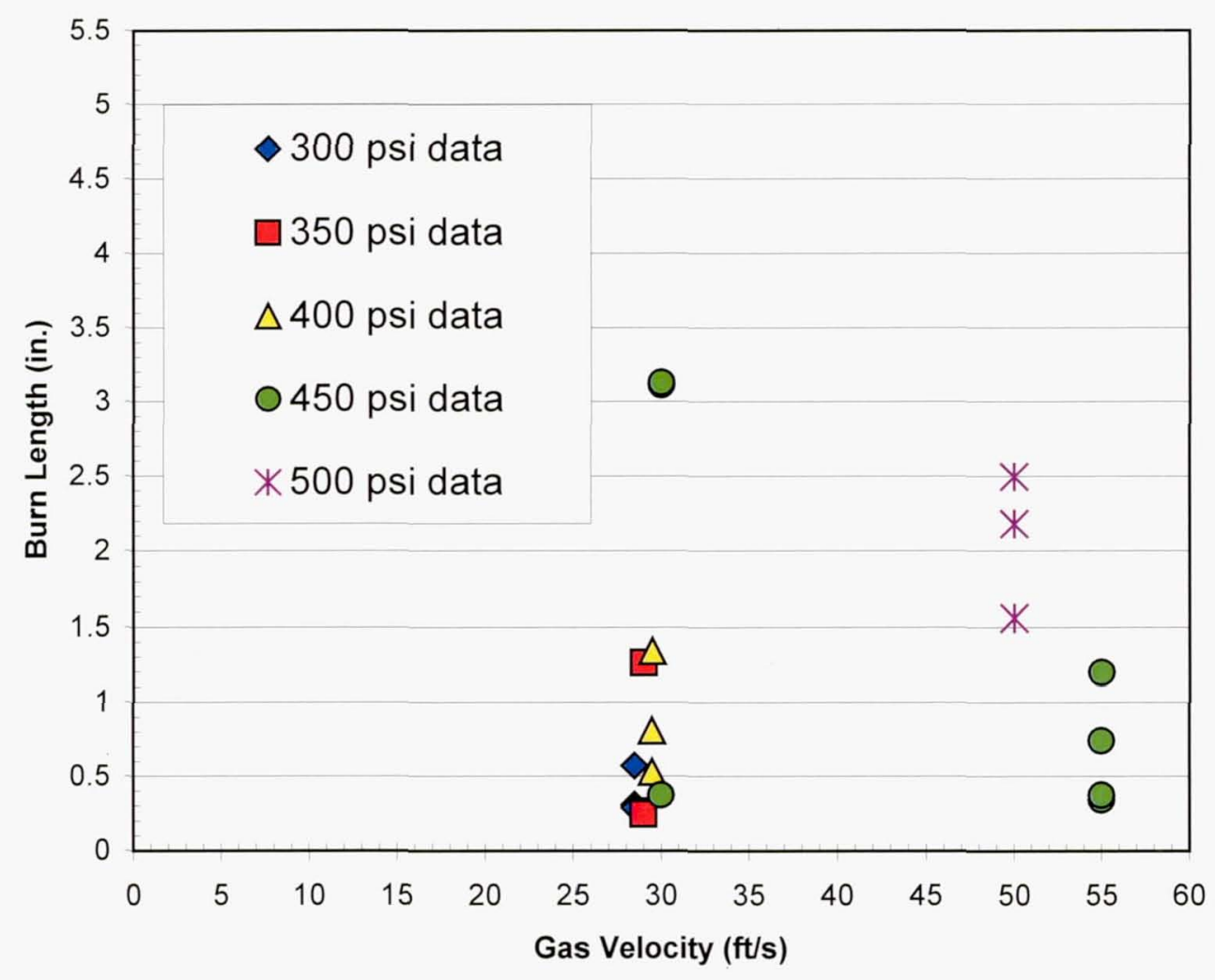

Figure 9 - Supplementary 1/2-in. rod test results. 
few positive ignitions seen at test conditions above $500 \mathrm{psi}(3.4 \mathrm{MPa})$ and $50 \mathrm{ft} / \mathrm{s}$ $(15 \mathrm{~m} / \mathrm{s})$. The data are significant in that they show that gas flow has a significant effect on sample ignition. Specifically, the data indicate that as flow conditions increased above $500 \mathrm{psi}(3.4 \mathrm{MPa})$ and $50 \mathrm{ft} / \mathrm{s}(15 \mathrm{~m} / \mathrm{s})$, the number of positive ignitions for this configuration decreased. The observed decrease may be due in part to increased heat loss mechanisms active in higher pressure, higher velocity environments.

CGA G-4.4 contains a well-known graph, often referred to as the "CGA velocity curve," for selecting materials for oxygen service based on gas pressure and gas velocity [1]. This graph provides guidelines, traditionally thought to be conservative, for the use of bulk stainless steel $(1$ in. $(2.54 \mathrm{~cm})$ NPS min. and $1 / 8$ in. $(0.32 \mathrm{~cm})$ thick min.). However, Program 96-1 Phase II data and other supplementary data discussed herein for $1 / 2$ in. $(1.27 \mathrm{~cm})$ stainless steel rods show the CGA velocity curve may not be conservative at some conditions. Figure 10 shows a partial graph of the CGA velocity curve, plotting gas velocities of $200 \mathrm{ft} / \mathrm{s}(60 \mathrm{~m} / \mathrm{s})$ and less, along with the positive ignition and self-sustained burning data for $1 / 2 \mathrm{in} .(1.27 \mathrm{~cm})$ dia stainless steel rods. CGA 4.4 guidelines permit the use of bulk stainless steel in gaseous oxygen at all conditions beneath the curve and temperatures less than $200^{\circ} \mathrm{F}\left(93^{\circ} \mathrm{C}\right)$. Figure 10 shows several conditions beneath the CGA curve where stainless steel promoted burning and, hence, conditions where stainless steel would be considered flammable if ignited. Thus, at these conditions, the CGA velocity curve is not considered conservative for stainless steel.

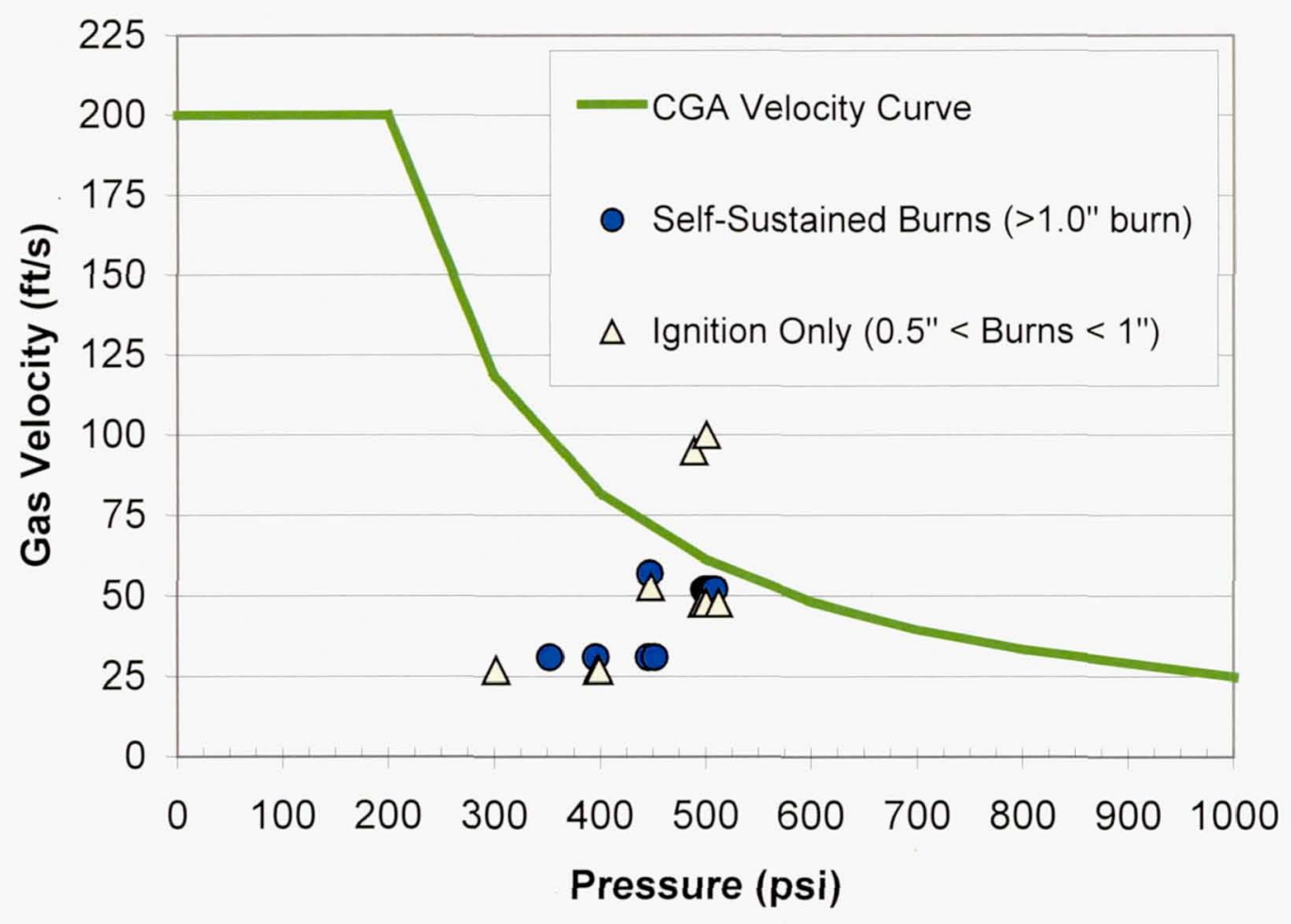

Figure 10 - CGA Velocity Curve with Self-Sustained Burn Data for $1 / 2$ in. $(1.27 \mathrm{~cm})$ dia Stainless Steel Rods. 
The 1 1/4 in. Sch. 80 and Sch. XXS pipe test samples showed results comparable to each other. Extensive attempts were made to design promoters capable of consistently igniting these samples, but still very few positive ignitions were observed for the Sch. 80 samples, and no positive ignitions were observed for the Sch. XXS samples at the conditions tested. At the given test pressures and velocities, it was difficult to overcome the pipe samples' resistance to ignition, even with several promoter configuration changes and increasing ignition energies. No nonflowing oxygen tests were performed on the pipe samples for comparison. But, similar to the rods, increasing the gas pressure and velocity on the Sch. 80 pipe samples decreased ignition probability, and few positive ignitions were achieved. Increasing gas velocity may act to cool the sample, and increasing pressure may allow greater heat transfer away from the sample into the environment, though more testing is required to confirm this.

Future testing may consider ways to achieve consistent positive ignitions in the pipe samples so that the effects of changing flow environments on burn length can be observed. It is recommended to consider using the Reynolds number, Re, as a test parameter for flow conditions in future testing since Re is a standard flow parameter incorporating both pressure effects and flow velocity. The Stanton number may also be considered as a beneficial way to evaluate thresholds for burning in flowing environments since it considers correlations of fluid friction and heat transfer.

Finally, Program 96-1 tests from Phases I and II, as well as supplementary flowing oxygen testing, showed that there can be significant differences in material flammability between a nonflowing and flowing oxygen environment. Though further testing and even flow modeling is required to understand which flow parameters (i.e., gas pressure, velocity, or others) most significantly influence flammability and how they influence it, caution should be used when attempting to apply nonflowing flammability test data to flowing environments. As always, when choosing materials for oxygen service, a conservative approach is recommended.

\section{References}

[1] CGA. Industrial Practices for Gaseous Oxygen Transmission and Distribution Piping Systems, CGA G-4.4, Compressed Gas Association, Arlington, VA, 1993.

[2] Benz, F. J., Shaw, R. C., and Homa, J. M. "Burn Propagation Rates of Metals and Alloys in Gaseous Oxygen", Flammability and Sensitivity of Materials in Oxygen-Enriched Atmospheres: Second Volume, ASTM STP 910, M. A. Benning, Ed., American Society for Testing and Materials, Philadelphia, PA, 1986, pp. 135-152.

[3] Benz, F., Steinberg, T. A., and Janoff, D., "Combustion of 316 Stainless Steel in High-Pressure Gaseous Oxygen," Flammability and Sensitivity of Materials in Oxygen-Enriched Atmospheres: Fourth Volume, ASTM 1040. J. M. Stoltzfus, F. J. Benz, and J. S. Stradling, Eds., American Society for Testing and Materials, Philadelphia, PA 1989. 
[4] Zawierucha, R. and Mcllroy, K., "Promoted Ignition - Combustion Behavior of Selected Engineering Alloys in Oxygen Gas Mixtures," Flammability and Sensitivity of Materials in Oxygen-Enriched Atmospheres: Fourth Volume, ASTM 1040, J. M. Stoltzfus, F. J. Benz, and J. S. Stradling, Eds., American Society for Testing and Materials, Philadelphia, PA, 1989.

[5] Zabrenski, J. S., Werley, B. L., and Slusser, J. W., "Pressurized Flammability Limits of Metals," Flammability and Sensitivity of Materials in Oxygen-Enriched Atmospheres: Fourth Volume, ASTM 1040, J. M. Stoltzfus, F. J. Benz, and J. S. Stradling, Eds., American Society for Testing and Materials, Philadelphia, PA, 1989.

[6] MIL-PRF-27210G(1). Oxygen, Aviator's Breathing, Liquid and Gas.

January 29, 2000. http://astimage.daps.dla.mil/online/parms/mainframe.cfm. Last accessed 8/11/02.

[7] NASA. Flammability, Odor, Offgassing and Compatibility Requirements and Test Procedures for Materials in Environments that Support Combustion.

NASA STD-6001, Marshall Space Flight Center, Huntsville, AL, February 9, 1998. 